Article

\title{
The Role of Participation in the Responsible Innovation Framework for Biofuels Projects: Can It Be Assessed?
}

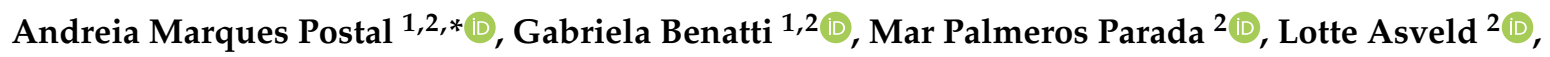 \\ Patrícia Osseweijer ${ }^{2}$ and José Maria F. J. Da Silveira ${ }^{1}$ (D) \\ 1 Department of Agricultural and Environmental Studies, Institute of Economics, University of Campinas, \\ Pitágoras 353, Campinas CEP 13083-857, Brazil; g.solidariodesouzabenatti@tudelft.nl (G.B.); \\ jmsilv@unicamp.br (J.M.F.J.D.S.) \\ 2 Department of Biotechnology, Faculty of Applied Sciences, Delft University of Technology, \\ Van der Maasweg 9, 2629 HZ Delft, The Netherlands; m.d.m.palmerosparada@tudelft.nl (M.P.P.); \\ 1.asveld@tudelft.nl (L.A.); p.osseweijer@tudelft.nl (P.O.) \\ * Correspondence: andreiamarquesp@gmail.com or a.camargomarquespostal@tudelft.nl; \\ Tel.: +55-19-9813-10-303
}

Received: 30 October 2020; Accepted: 10 December 2020; Published: 17 December 2020

\begin{abstract}
The growth in biofuels' investment brings with it concerns about the social and environmental impacts of the sector. Several tools and frameworks have been used to address these concerns, including the Responsible Research and Innovation (RRI) framework. This paper analyzes whether this framework can be applied in contexts where local culture and values shape differently the freedom of speech and engagement, such as in developing countries in which biofuel innovation projects are often implemented. A literature review focused on eight case studies of other authors was used to explore the role of "participation" as a structural element of the RRI framework and the impact of its absence where effective participation in the innovation development process is not possible. In conclusion, we highlight how this inspirational normative framework, designed to influence innovation, is misused to judge its impacts. More than that, the conclusions of such misused applications reflect more the difficulties involved in applying guidelines than the responsible character of the innovation, whose impacts are usually defined upfront materially and measurably.
\end{abstract}

Keywords: responsible research and innovation; biofuels; effective participation; inclusion; institutions

\section{Introduction}

There is a growing demand for alternative, renewable energies. One of them is biofuels, which are well-suited to the transport sector due to their liquid form and the diversity of raw materials and potential local production sources. However, along with the growth in this sector's investments, concerns have emerged regarding social and environmental impacts, such as land-use changes, food security, and biodiversity loss.

Different frameworks and assessment tools have emerged to analyze these social and environmental impacts, among them, the Responsible Research and Innovation Framework (RRI). The RRI framework was first employed in Europe after the economic crisis of 2008 and introduced the consideration of values and concerns related to innovation. As an inspirational normative framework aimed to influence researchers and innovators through its four pillars, the framework played a relevant role in the development of research and innovation in Europe since it was adopted by important research institutions in The Netherland and UK and is a transversal guiding principle of the "Horizon 2020 Research and Innovation Program" from the European Union [1-6]. 
However, biofuel projects are implemented in Europe's technological innovation centers and the US and countries far from the developed countries where the framework was created. As different cultures and values have different ways of interacting and building solutions, we must consider whether the use of the RRI framework truly reflects the responsible nature of innovation itself or whether it reflects the difficulties involved in applying guidelines that were, perhaps unconsciously, embedded with western values. Section 2 presents how the analysis through a literature review focused on case studies (from the biofuel and other sectors). The research about the framework's structural elements was used to complement the analysis and reach more accurate conclusions about the responsible character of innovations.

Section 3 describes the growing importance of biofuels in the transition towards a biobased society and some of this sector's characteristics. Section 4 is dedicated to exploring the origin and aims of the RRI framework to analyze innovation's responsible character. Aspects such as the participatory process and stakeholder engagement are at the core of the framework's recommended activities. However, the inclusiveness dimension encapsulates them and, because of that, demand more attention to the effectiveness of all other dimensions. These reflections highlight the processual meaning of the term "inclusion", as well as the meaning of the term "responsible" and the impact of these characteristics on the application of RRI in contexts where different values and behaviours shape matters of participation and engagement.

In Section 5, we introduce the "institutional approach" as a possible complementary analysis to understand these different contextual elements which shape the participatory process and the application of RRI. Institutions have a dual role: as "action arenas" or deliberative forums where stakeholder discussions take place and acquire deliberative functions and coercion; at the same time, institutions are key elements in understanding the local context, culture, values, and behaviors. Section 6 discusses what happens when such institutions are not in place, illustrating several case studies carried out by other authors. These cases are analyzed to understand RRI applicability's limits as an assessment and the institutional analysis's complementary role.

Finally, we describe the research's main conclusions about using RRI in assessments to describe the "responsible" character of innovation and complementary ways to improve the analysis.

\section{Methodology}

We conducted a literature review using the Web of Science and Science Direct. The search terms on topics included "responsible research and innovation," "responsible research and innovation AND biofuel", "responsible research and innovation AND bioeconomy", "responsible research and innovation AND developing countries", "responsible research and innovation AND global South", "responsible research and innovation AND southern countries", and "responsible research and innovation AND South America". An overview of the search procedures is presented in Figure 1.

Details about the selected studies are in Table 1 . The articles are presented in the table by alphabetic order of authorship. 
Table 1. Articles selected.

\begin{tabular}{|c|c|c|c|c|}
\hline Authors & Title & Year of Publication & Studied Location & Innovation Focus \\
\hline Balkema, A.; Pols, A. & $\begin{array}{l}\text { Biofuels: Sustainable Innovations or Gold Rush? Identifying } \\
\text { Responsibilities form Biofuels Innovations }\end{array}$ & 2015 & Tanzania & Jatropha biofuels \\
\hline Chaturvedi et al. & $\begin{array}{l}\text { Agriculture Technology Choices and the (RRI) Framework: } \\
\text { Emerging Experiences from China and India }\end{array}$ & 2016 & India and China & Transgenic cotton \\
\hline De Campos et al. & $\begin{array}{l}\text { Responsible Innovation and political accountability: } \\
\text { genetically modified mosquitoes in Brazil }\end{array}$ & 2017 & Brazil & $\begin{array}{l}\text { Genetically modified } \\
\text { Aedes Aegypt }\end{array}$ \\
\hline De Hoop et al. & Limits to responsible Innovation & 2016 & India & Jatropha biofuels \\
\hline Hartley et al.. & $\begin{array}{l}\text { A retrospective analysis of responsible Innovation for } \\
\text { low-technology Innovation in the Global South }\end{array}$ & 2019 & Europe and Africa & Low technologies \\
\hline Macnaghten et al. & $\begin{array}{l}\text { Responsible Innovation across borders: tensions, paradoxes } \\
\text { and possibilities }\end{array}$ & 2014 & Cross-cultural & $\begin{array}{l}\text { RRI from a cross-cultural } \\
\text { perspective }\end{array}$ \\
\hline Vasen & $\begin{array}{l}\text { Responsible Innovation in Developing Countries: } \\
\text { An Enlarged Agenda }\end{array}$ & 2017 & Developing countries & $\begin{array}{l}\text { RRI in Developing } \\
\text { countries }\end{array}$ \\
\hline Voeten, J.J.; Naudé, W.A & $\begin{array}{l}\text { Regulating the negative externalities of enterprise cluster } \\
\text { innovations: lessons from Vietnam }\end{array}$ & 2014 & Vietnam & Small informal enterprises \\
\hline
\end{tabular}




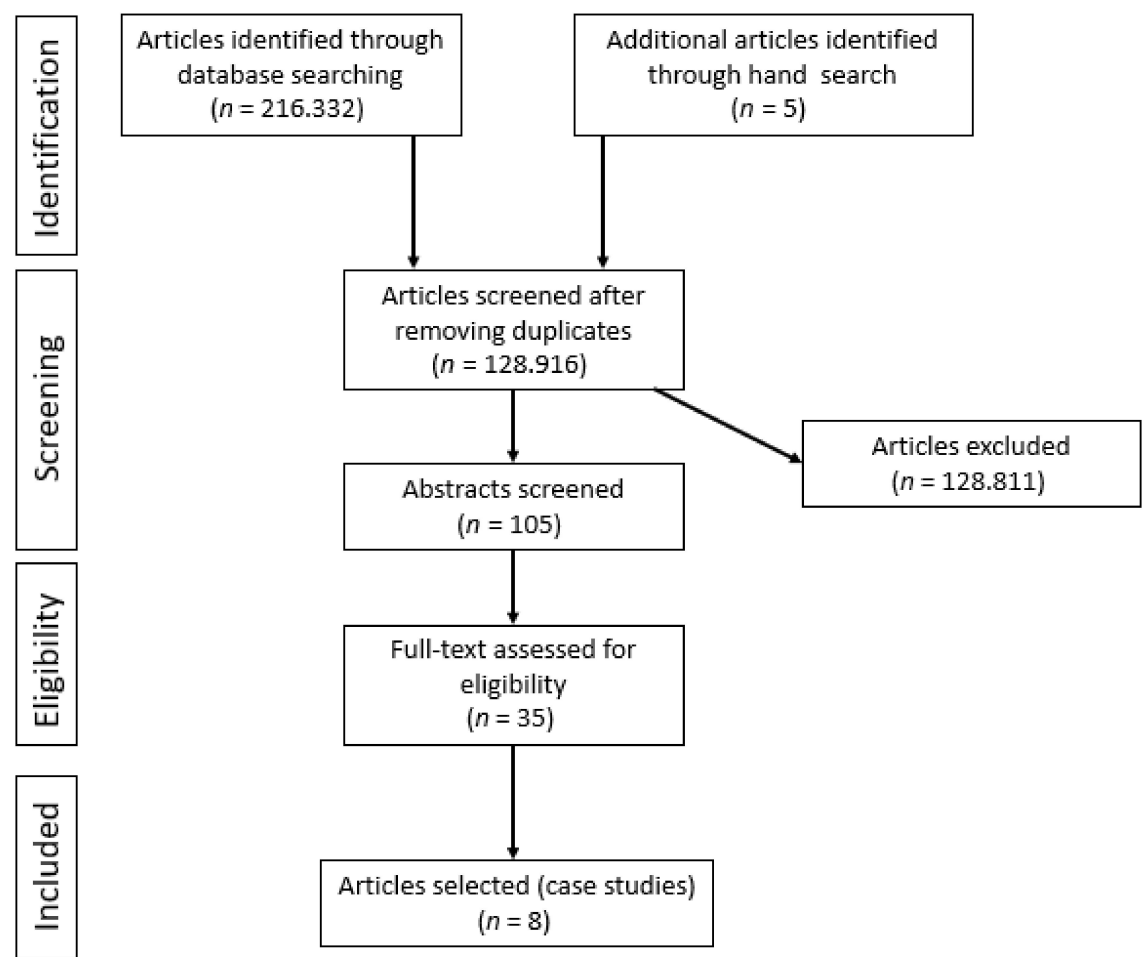

Figure 1. Search procedures.

\section{Biofuels as Cleaner Energy and Global Commodity}

The worldwide concern about fossil fuels, both in terms of their environmental impact and energy security, has resulted in searching for alternative energy sources to replace or supplement countries' energy matrix. Such alternative energies include hydropower, wind, solar, geothermal, and biofuels, as presented in Figure 2.

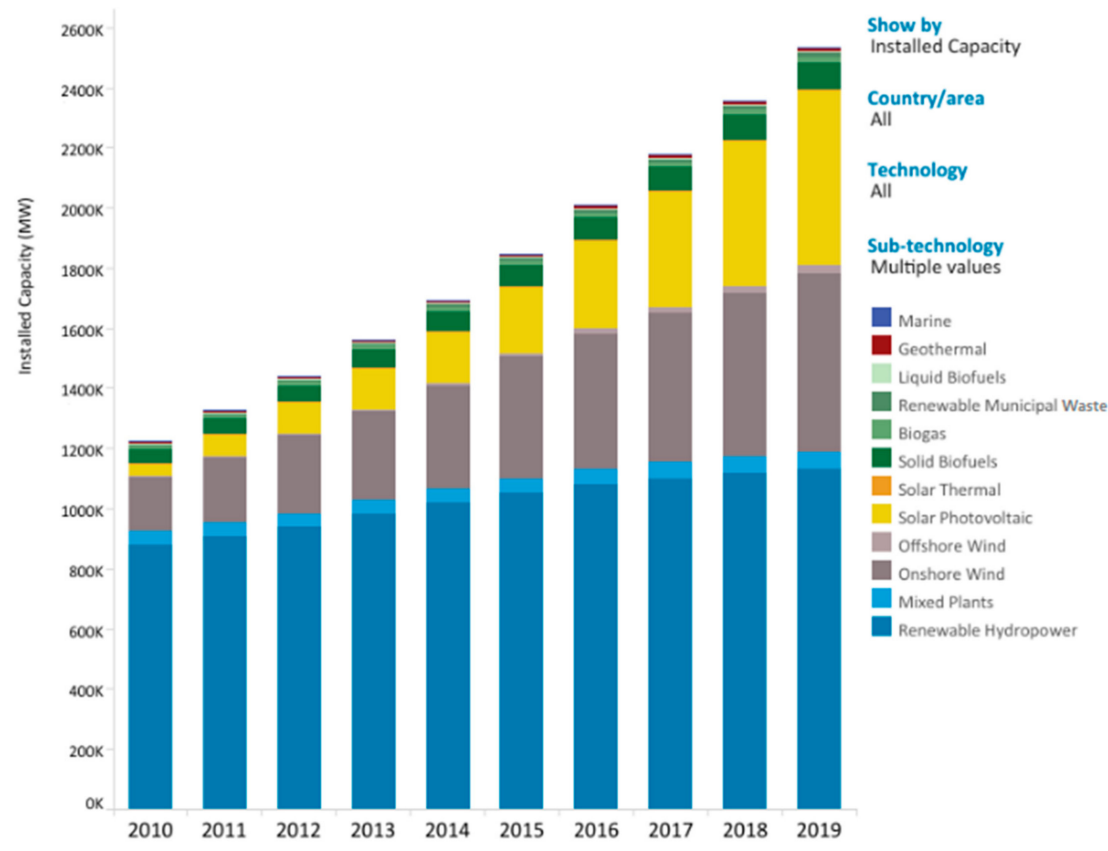

OIRENA..

Figure 2. Global installed capacity of renewable energies [7]. 
Biofuels have been developed for some time now as a renewable, drop-in alternative for fossil fuels. They are well-suited for use in the transport sector. Their liquid form favours transportation to the final consumer and can be easily incorporated into the existing distribution infrastructure, for example, through blending [8]. This makes biofuels an essential energy source in the transition from fossil fuels to clean energy. However, the global renewable energy debate is now shared with other alternatives, especially wind and solar PV, whose investments have grown significantly $[9,10]$. Support for renewable energies and energy efficiency in road transportation largely occurs by incentivizing biofuels, electric cars, and fuel efficiency. Another benefit of biofuels is that they can be obtained from various raw materials produced in a range of locations, which may improve countries' autonomy and energy security and reduce their dependence on fossil fuels.

Many countries now have blending targets in place, which has led to an increase in the demand for liquid biofuels, especially in the United States, the European Union (EU), and Japan, and reflected a rise in the trade and import of biofuels, such as Brazilian ethanol, Jatropha, palm oil, and other sources of vegetable oil and biodiesel, from the United States, Latin America, and Southeast Asia. The production of biofuels has created new markets, and energy trade flows worldwide [11]. Based on the international liquidity of capital during the 2000s and the increased demand for biofuels worldwide, several investments were made in different countries, in other crops and contexts.

\subsection{Concerns about Biofuel Expansion}

However, the growing demand and investment in biofuel production implied new environmental and social concerns. Questions about the impact of biofuels on land-use changes [12-14], food security [15-18], deforestation and greenhouse gas emissions [19-22], have formed the core of the biofuel expansion debate [23-25]. The literature recognizes different types of impact depending on the source of the biofuels (1st generation, 2nd generation or biodiesel). However, the usefulness of an assessment approach to verify the extension of those impacts keep useful regardless the type of the biofuels in question.

On the other hand, positive aspects have been added to the food/energy/forest "trilemma" debate [26-28] to analyze the trade-offs involved. Examples include job creation and improved working conditions in the value chains [29-32], rural development [33-35] and integration with smallholder farming practices [36]. Therefore, if biofuel production is to attain sustainable decarbonization and other renewable energy targets, the societal context must prevent or minimize negative outcomes and increase benefits.

\subsection{How to Address These Concerns}

In Brazil, where developments in the bioenergy sector are centered on advanced biofuels (first-and-second-generation ethanol), interest has been shown from relevant sectors to address these concerns. Emerging bioenergy sectors include, for example, second-generation ethanol, new drop-in applications such as jet fuels, and the diversification of biodiesel sources and technologies for lignin extraction. The processes involve mature technologies and intermediate and emergent sectors [37,38]. This interest is illustrated by the growing partnerships between biofuel developers and users, and societal actors such as NGOs, as well as their participation in voluntary sustainability certifications such as the Better Sugarcane Initiative, now Bonsucro (https://www.bonsucro.com/), Roundtable on Sustainable Biofuels (https://rsb.org/) (RSB), among others [31,39-41].

One way to address societal concerns is to influence the researchers and entrepreneurs when the innovation is at the initial stages of development. In Europe and the United States, Responsible Research and Innovation (RRI) guidelines were drawn up to increase all interested stakeholders' participation to promote the alignment of social needs and values with the technology being developed [42,43]. Besides its use as an analytical framework, the RRI approach can address emerging societal and environmental concerns in ongoing developments in the biofuel sector or any other emerging technology field. The implementation of RRI is not only in the interest of the public and the RRI community but also in the biofuel sector's interest in addressing concerns. 
However, since many biofuel projects are implemented in developing countries in the Global South $[4,44,45]$, it is not clear whether the RRI approach can be used in contexts other than Europe for this purpose. In the following section, we describe the main concepts of the RRI framework and the reasons for these doubts.

\section{The RRI Framework and the Role of "Participation" in Innovation Projects}

The RRI approach fundamentally looks to generate ethical practice and awareness by influencing emerging technologies in innovation research and ventures. The strategy to do so is to inspire the innovation process through the effective participation of a range of stakeholders that guarantee the consideration of sustainable aspects in socially desirable projects and, in doing so, respond to the main problems faced by humanity $[1,42,43,46]$. Its design emphasizes that innovation is a collective action involving several agents and institutions engaged at all stages of the process, from agenda-setting to design, implementation, and evaluation. Agents include researchers, policymakers, educators, entrepreneurs, and civil society organizations, encompassing the people directly impacted by the innovation. These ideas were promoted by the EU and incorporated, for example, into the Dutch Research Council (NWO) guidelines, and as a result, spread throughout the academic arena in Europe and the US [47]. It is important to note that the societal context that shaped this framework was marked by essential debates in society on ethics, the role of science and innovation, sustainability, climate change, nanotechnology, and increasing demand for participation in the decision-making process in democratic societies [48].

However, the framework presents some limitations [1,49-52]. Its normative character is considered one reason why it doesn't have a central role in Horizon Europe. However, its principles and aims remain relevant in the context of this new phase of the European research agenda and academic debates. In this section, we aim to analyze how "effective participation" is a core attribute for its four pillars' efficiency and, therefore, a reason why using the scheme as an assessment tool is inappropriate. This is because local culture and historical contexts shape the ways of interaction in each country or region differently and, therefore, produce variable results in the process of participation and applicability of RRI pillars, which may have no connection to the positive impact of the innovation itself.

\subsection{The Main Pillars of RRI}

The framework was built based on four main pillars that continuously reinforce each other. The proposed dimensions have been broadly accepted as requirements for responsible research and innovation through normative guidelines, although many authors have made amendments and additions. The framework is meant to be used as a proactive and inspirational guideline to meet societal expectations. Therefore, its use in a retrospective way should be avoided or, at least, used with care to avoid conclusions and judgments over innovation impacts while assessing just the innovation development process. The same holds for actors and activities that were not planned to be aligned with such a framework built afterward. We also question its use as an assessment tool due to the lack of objectivity and defined comparable parameters.

According to Stilgoe et al. [43], the four dimensions are:

- Anticipation: to consider what we know and what is probable in terms of technology use. Anticipation aims to foresee the potential risks of the new technology and require a "well-timed" approach to be meaningful and constructive. Another essential requirement is "transparency" since the shared knowledge and information are crucial to enabling participants to assess the risks and future impact of innovations [1].

- Reflexivity: to recognize the moral views, interests, and roles of all relevant stakeholders and critically examine the assumptions behind them. Stilgoe et al. [43] also highlight that reflexivity should be present not only at the laboratory level but mainly at the "institutional" level (research funders, regulators, and other institutions). These organizations should help build the reflexive capacity 
among engaged stakeholders and reflect on their value system, shaping the innovation process. To do so, the independent thinking of the participants is crucial.

- Responsiveness: the capacity to respond to the questions and insights raised during the innovation process. In this sense, the "actors" involved should have enough power, resources, capabilities, and skills to do so. According to Stilgoe et al. [43], it implies the notion of innovations being shaped so that they are "as responsive as possible" to the adjustments that occur throughout their development while recognizing the insufficiency of knowledge and control. However, the authors point out the need for diversity (of stakeholders) to have a responsive innovation system.

- Inclusion: refers to how relevant stakeholders are engaged in the innovation process. To achieve qualified outcomes of the inclusiveness process, Stilgoe et al. [43] refer to three criteria as proposed by Callon [53]: intensity, or how actors are invited to participate promptly; openness, in other words, how the group is composed and how diverse it is; and the quality of the discussion which depends on the participants' critical thinking skills.

One crucial challenge highlighted by the author regards the power imbalance among the participants, which can jeopardize discussion outcomes. Additionally, issues such as confidentiality, information asymmetry, and power imbalance are frequently observed during the use of the approach. All these elements highlight the importance of effective participation to achieve "substantive inclusion," which can achieve the framework's aimed outcomes [49].

\subsection{RRI Demands an Effective Participatory Process}

Through its architecture and dimensions, the RRI framework emphasizes inclusion as a process of participation and engagement, and this is based on a belief that, if this processual inclusion is well-executed (effective participation), we will have a substantive inclusion [49], the stakeholders will together be able to build the best solution (or material results), taking into account society's needs and the interests of all groups. This characterizes RRI as a processual framework where the stakeholder's inclusion and participation are key to achieve the desired societal outcomes brought to the table by these participants [50]. Participation is, therefore, a key element to the successful execution of all RRI dimensions. Still, it requires the right set of stakeholders to produce results aligned with the RRI framework effectively. The right set of agents, who would be chosen or invited by trustable organizations, would have characteristics such as representing a diverse range of stakeholders, consisting of independent skilled people with a high level of critical thinking who can discuss and avoid manipulation. Only the right set of stakeholders in a process coordinated by a trustable organization would deliver the anticipation, reflexiveness, and responsiveness dimensions required by the framework.

Therefore, it is reasonable to deduce that the term "responsible", as pursued by the RRI theoretical framework, is directly related to organizing a participatory process (by inviting relevant audiences who would perform the four pillar activities) effectively. This "effective participation" could ensure the four pillar activities' satisfactory performance while indirectly achieving the innovation process's material outcomes. What are the requirements for "effective participation" in the implementation of a biofuels project?

We understand that two requirements are essential to guarantee an effective participatory process to achieve the final goal of the RRI approach: (a) an adequate set of stakeholders and (b) adequate institutions for coordinating the process and working as an "action arena with deliberative power to achieve"responsible innovation impacts.

The former, referring to the set of stakeholders, is relevant since the outcomes of each one of the four pillars are not given upfront but are defined by the participation and positioning of the group of invitees representing their interests. It can also be extracted from an in-depth analysis of the four pillars' implementation [43]. Each one of the posts requires specific attention to the definition of representativeness to attain the best results. Thus, the anticipation pillar requires a well-informed and diverse range of participants who can challenge and question potential risks. The reflexiveness 
pillar requires stakeholders' independence, the ability to rethink moral values, enriched with different stakeholders' perspectives. The responsiveness pillar requires openness, transparency, and response capabilities, which can only be attained through the participants' assertive group invited to the process. Finally, the inclusiveness itself requires different views from a range of interests and fields (scientists, governments, laymen, community leaders, and external experts) with different perspectives and a good representation of society.

Therefore, effective participation is a crucial element to discuss the future perspectives of emerging biofuel technologies, which are inherently uncertain and depend on the set of representatives' best configuration. Thus, it is necessary to consider the requirements these actors must fulfill to reach the process's best outcomes.

In fact, "effective participation" assumes that some values are present or given in any context or society [48]. However, the forms and patterns of interaction among stakeholders seem to differ in each country or region [51]. It is crucial to understanding how the local context, culture, and beliefs interfere with and shape the discussions on achieving the desired responsible innovation. This is particularly important when discussing research and innovation, which are developed in one place and implemented in another, as is usually the case of biofuels and other technological innovations $[48,52,54,55]$.

Effective participation is related to the definition of groups and names and a second important element: the institutions where the discussions take place. This element from institution analysis theory [56] is usually responsible for answering organizational questions: when does the discussion occur? Is the frequency of meetings sufficient? Are the meetings multidimensional or just one-way communication events? Where do these meetings take place? Are all stakeholders able to attend? How do people interact with each other? How much freedom do they have to speak freely? How do gender and religion affect the ability to speak out and develop the right solution for everyone?

Answering these questions is out of this study's scope; nevertheless, they are mentioned here as they reveal the importance of understanding local practices. Some of these details are efficiently managed; others, however, are more difficult to deal with since they have hidden rules, behaviours, and beliefs that are difficult for an external stakeholder or an assessment body to understand and create global metrics to measure it, especially when discussing transcontinental projects where long distances impact closer coordination and recognition of context limitations [57]. In all cases, institutions are critical to effective participation and responsible innovation analysis. Because of this, their importance is further explored in the following section.

\section{Institutions as Key Elements of the Innovation Process Analysis}

Social and economic structures give rise to different configurations of actors in different countries at different times, who exercise influence not only on the making of policy but also on the making of institutions [58].

\subsection{Institutions as a Proxy for the Local Context}

Barney et al. [59] define an institution as an organized pattern of constitutive collective behaviour and its evolution. In this sense, institutions are made up of values, norms, beliefs, meanings, symbols, customs, and socially learned and shared standards, which define the range of expected and accepted behaviour in a particular context. Aligned with this, Taebi et al. [52] explain that technological development occurs in specific institutional contexts involving individual stakeholder dynamics. These contexts, constituted by formal and informal institutions, reflect values that have significant ramifications for the governance structure, the distribution of power between stakeholders, transparency processes, gender equality, and the definition of priorities.

Echebarría et al [58] explains that institutions are path-dependent since the historical facts influence institutional evolution and its characterization. The institutional path and the social development path are not easily comparable or compatible with each other historical, economic, social, political, and cultural aspects influence the constitution of an institutional network, establishing specific and 
local forms of the development pattern [60]. All these factors set the limits within which the actors involved in these processes can act. Specifically, with regard to impact assessment, the mentioned factors can also limit the supervisory role of the responsible institutions. There are difficulties in carrying out impact analysis, financial and methodological challenges stand out. Once these studies are in place, even if measurable, there are also limitations in translating the results into norms and laws, and incorporating them into policies and the policy agenda.

In their place, important debates or frameworks can create resistance from stakeholders, as local organizations or society. The main reason is that, in general, these models are impregnated with values and realities that are very different from the local ones. In this sense, the network with other organizations and institutions is important to maintain objectives and inspire adaptations. Then, local multilateral organizations can act on adapting more general parameters to local realities at the more concrete level, we can mention agencies responsible for the regulation of biofuels, social policies and rules, even civil society represented by NGOs. The institutions, treated on a more general level of action arenas, manifest themselves in a dispute in the general plan of laws, rules, values and behaviours. This arena starts from the parliament, responsible for formulating rules and laws. In democracies, the members of the parliaments are elected, which theoretically, gives them independency to challenge agencies, institutions, organizations, and even the government [58].

Ostrom [61] also emphasizes the importance of local context, stating that exogenous variables such as (a) the biophysical and material conditions; (b) community attributes, including values, behaviours, and traditions; and (c) rules-formal and informal—-that affect the action arenas (or institutions) where a group of participants (or stakeholders) interact with a specific purpose (or action situation). In this approach, "action arenas" shape and characteristics depend on the local contexts' exogenous variables.

Therefore, we argue that institutions are a proxy for analysing and incorporating local context specificities and that RRI should take these aspects into account. After all, each context manifests a specific reality that can impact the implementation of the dimensions and objectives of RRI. Incorporating these aspects would enable researchers and policymakers to shape and adapt the framework elements to the specific necessities regarding responsibility in the research and innovation processes.

Understanding the institutional contexts is important since limitations concerning the implementation of RRI may be more related to broader and deeply rooted socio-political factors and institutional contexts than to specific initiatives. Regarding this, Wickson and Carew [62] classify the "clear and explicit identification of institutional and contextual limitations and a structured effort to acknowledge and improve upon these conditions" as an exemplary criterion of reflexiveness and responsiveness.

\subsection{Institutions as "Action Arenas" for Innovation Process Discussions}

Another critical factor in incorporating an analysis of institutions into the RRI approach is that they represent the arena (or deliberative forum). The controversies surrounding and evolution of the innovation process occur. In Ostrom's words, an "action arena" is the "social space where individuals interact, exchange goods and services, solve problems, dominate one another, or fight" [56]. In sum, action arenas are collective spaces where the participation process takes place and, because of this, the characteristic of institutions is fundamental.

The question arises: which factors differentiate contexts with weak institutions from those with strong institutions? How is this linked to a potential RRI application? Levitsky and Murilo [63] highlight some features that support the differentiation of these institutional contexts: (1) socioeconomic inequality, (2) institutional borrowing, and (3) hasty institutional design.

Socioeconomic inequality is a factor that contributes to distancing society from important debates, particularly in contexts where there are low levels of education and access to information. There is a reduction in society's confidence in the institutions. Institutions are often imported from abroad without reflecting on the alignment with pre-existing domestic power structures or norms, leading 
to discrepancies. The rapid institutional design, in turn, affects institutional quality and durability, as there is inadequate time to anticipate impacts, include stakeholders, or further discuss issues.

Based on the argumentation described earlier, nations with a strong institutional configuration can conform to the RRI principles more easily than countries with a weak structure. The difficulty lies mostly in the concentration and imbalance of power, the lack of collective prioritization, aspects that impair representation (such as educational level), and political instabilities, to give some examples [63,64]. There may be no commitment to being "responsible" in these local contexts, one of the RRI framework aims.

To summarize, we have so far argued that (1) institutions are a proxy of local context and because of this can be used to improve strategies to implement RRI approach, and (2) institutions work as action arena or deliberative forum and are fundamental to coordinate the participatory innovation process. In the following section, we aim to illustrate these two points by presenting selected case studies from outside Europe (based on literature) that used RRI as an analysis tool to show how they failed to be objective and provide relevant comparisons. Several studies indeed illustrate the relevancy of the impact of institutional context on the performance of RRI pillars.

\section{The Weaker the Institutional Context, the Harder the Effective Participation and Application of the RRI Approach}

Following the previous section, institutions play an essential role in coordinating the innovation process since they represent the local context's crystallization. At the same time, institutions act as an approximation for understanding the values and behaviours behind how people interact and work as a "locus" or as an "action arena" that legitimizes the outcomes of such interactions. Therefore, the quality of the institutions is essential since it controls the different ways that stakeholders interact, different levels of effective participation and, thus, impacts the ability of members of the local community (researches, entrepreneurs, policymakers, NGOs) to perform RRI activities to achieve responsible innovation process effectively.

Strong institutional contexts facilitate the effective participation of stakeholders. In such cases, RRI guidelines, which demands freedom of speech, gender equality, power balance, among other attributes to perform effective participation, are easier to apply, and the results from the participatory process can be interpreted as an indication/good representation of how participative the innovation process is. On the other hand, the effects are the opposite in the case of weak institutions when the participatory process required by the RRI framework can be jeopardized by a lack of coordination in the process of engagement, an imbalanced discussion impeding the free access to information and freedom to speak out [65].

It is the case for most biofuel innovation implementation processes since biofuel production often occurs in rural areas in developing countries, far from the large urban centers where the developers of the technology or the framework's creators are found. It highlights the inherent difficulties in the implementation phase in regions where the culture of participation, history, and economic context are very different from the Western developed countries, where these contextual RRI elements are largely accepted and implemented through traditional and robust institutions. Brazil is an interesting case since it is considered technologically developed and with good institutions. However, due economic history, cultural values, and deep inequality context, the implementation phases are often done in top-down manner and therefore, is not aligned with the participative process as required by the RRI framework. Even though this lack of participation in the implementation process of biofuels projects, the outcomes of these projects for the local communities seem to point to inclusive impacts [66]. Timmermans [6] described the RRI approach as still a "predominantly Western affair". The absence of credible and stable institutions can jeopardize the free and effective participation of less privileged people who may not have full knowledge of their rights or access to information and, consequently, may have a limited capacity to analyze innovation's potential issues.

In a case study carried out in Tanzania described by Balkema and Pols [67], Jatropha's investments were stimulated by the $2003 \mathrm{EU}$ directive to promote biofuels. However, the authors noted that small 
biofuel producers were left behind in the discussions on Jatropha's expansion. The "exclusion" of this vital stakeholder has led to missed opportunities. Considering this "weak inclusion" or failure to assure "effective participation" of the right set of agents, the authors claim that the EU failed to anticipate the impacts of its biofuel policy and did not include small farmers' voices.

There was a shift in expectations regarding biofuel production from Jatropha from the large-scale cultivation of a "miracle culture" that could provide sustainable biodiesel for Europe to a "biofuel niche culture". It turns to be viewed as a crop with relatively low yields, suitable for bio-oil production for local use. The authors conclude that the impacts of large-scale production of Jatropha have contributed to a series of problems that conflict with sustainability ideals, such as food insecurity (through land-use changes that negatively impacted food planting), the marginalization of small farmer participation as an actor of interest, loss of soil fertility and biodiversity loss. They, therefore, concluded that the case has proven to be unsustainable and irresponsible.

However, the article did not analyze the role of Tanzania's historical and economic context. How can an external institution such as the EU, with such a major difference in values and culture to an Eastern country, be responsible for identifying the legitimate stakeholders who should sit at the negotiation table? To what extent did small-scale farmers trust the process and the mediators? Were these farmers able to make their voices and concerns heard? It seems that the lack of a local institution as coordinator, with a better understanding of Tanzania's context and traditions, has jeopardized the whole RRI process, failing to establish an adequate set of engaged stakeholders.

Therefore, what can be concluded from the use of RRI in this case study is the failure to achieve effective participation. These failures led to a poorly implemented innovation with negative impacts. The "irresponsible character of the innovation" is connected with the implementation process and not with the biofuels innovation's direct material impacts in this local context. Indeed, we could judge biofuels as irresponsible if the framework had specific impact criteria to do so. For example, about food security (total food imported versus locally produced), loss of soil fertility (percentage of fertilization need compared to the past), and biodiversity loss (percentage of deforestation). Although RRI is about meeting grand challenges and aligning with society's values, the framework does not have these direct material criteria. Material issues as food security, loss of fertility, biodiversity loss, and others can appear if, and only if, the chosen set of invited stakeholders effectively participate in the discussions and bring those themes to the negotiation table. Instead, the RRI as a normative processual framework has the criteria of inclusiveness, which were done without considering institutions. Then, its results are not enough elements to judge the impacts of the innovation itself as irresponsible.

In another study on India, De Hoop, Pols, and Romijn [44] studied a Jatropha project carried out by the University of Agricultural Sciences in Bangalore (an entrepreneurial actor with an academic profile). One of the project's main goals was to improve the natural environment's quality and the lives of the people involved (inclusion as an outcome). In practice, however, several problems were highlighted due to the lack of proper inclusion of local producers in the project's design (inclusion of process or effective participation). Although the authors mention that the process respected the inclusion pillar, they expressly pointed out the low quality of involvement, which meant that farmers failed to adhere to the project due to restrictions on water access for irrigation (failure in participation implied failures in anticipation process activities). Both the farmers and the researchers had to deal with power structures. The local institutions responsible for carrying out the process were not strong enough to mediate these power differences or effectively include a range of stakeholders and guarantee their right to free speech (failure in responsiveness). The authors concluded that, although the project did not negatively impact the local population and the environment, it also did not result in the expected positive impacts. The authors present evidence that the project did not sufficiently meet the four dimensions of RRI. Therefore, it concluded that the innovation project should not be implemented since RRI is about 'innovating responsibly—or not innovating at all' [44] (p. 129).

However, our interpretation of the proposal of Stilgoe et al. [43] together with other authors on institutional theory such as Ostrom [56] and Acemoglu and Robinson [60] leads us to conclude 
otherwise. We understand that due to the lack of effective local actors' participation, the inclusion, anticipation, reflexivity, and responsiveness dimensions were jeopardized. There was no vital institution to lead the project that impaired the RRI dimensions, and idiosyncrasies emerged. For example, should a university that does not have an entrepreneurial mindset be responsible for carrying out a "business enterprise" with all inherent conflicts of interest of these roles? Should universities be responsible for advocating biofuel policy or negotiating trade agreements with biofuel dealers? Would the recommendation of "abandoning the innovation process", as proposed by the authors, be considered a well-thought-out and fair decision for the local community? Would that put the potential positive impact of the venture at risk just because it did not meet the expectations of participation included in the assessment tool created according to values different from the local culture? Again, the question is posed: should this conclusion be interpreted as a failure on the part of the biofuels project in India or the failure to adhere to, adapt, and implement the core RRI concepts? The analysis must first examine contextual elements of governance and local institutions in greater depth to be considered valid alternatives. After all, is it better to achieve some benefits or no benefits at all? The academic community must address this ethical question.

The two cases above did not consider the local contexts in their analyses to interpret the "possible participation process" to be implemented. As a result, we understand their conclusions reflected more a lack of adherence or adequacy of the RRI process to those contexts than the "irresponsible character of the innovations developed" in terms of its potential impacts. Both cases make conclusions about the final impacts of the innovation (calling them irresponsible or suggesting to give up the innovation) using an assessment tool (RRI) that focuses mainly on its development's participatory process. When the participation is not ideal according to RRI requirements, instead of analysing the role of institutions that coordinate the process, the author criticizes the innovation itself's potential impacts.

In contrast, reflections on the RRI approach's limits and claims for a local context analysis through an institutional approach were echoed in several studies. Chaturvedi et al. [68], for example, analyze governments' role in defining the pathways to develop innovations in the transgenic cotton sector. The authors highlighted the lack of transparency (China) and credibility (India) as evidence of weak institutions that jeopardize the RRI process and responsible innovation. Hartley et al. [69], from a different angle, analyzed the difficulties in implementing low-tech innovations using the RRI approach in transcontinental projects (Europe and Africa) and, even when the research team considered the approach, the "inclusion pillar" reflected "a process of discursive exclusion." In the case of Vietnam, Voeten and Naudé [70] analyzed the impact on weaker institutions' responsiveness dimension previously coopted by entrepreneurs. They were unable to coordinate the process to reap benefits for society as a whole.

In Latín América, de Campos et al. [71] defend an interconnection between the notion of political accountability (one aspect of responsiveness) and institutions, since the difficulty in predicting the trajectory of innovation and the absence of a deliberation arena can strongly impact the innovation trajectory of a vaccine for the dengue mosquito. Macnaghten et al. [45] and Vasen [65] explore the difficulties and limitations of employing the RRI framework in contexts with different capabilities, values, and institutions, and the risk that this can be perceived as a new model of intellectual neo-colonialism.

Figure 3 represents how the complementary analyses of institutions can help define strategies to implement the RRI approach to achieve the effective participation required and how to analyze the results of the RRI application when the local institutions are not capable of achieving an effective participatory process. 


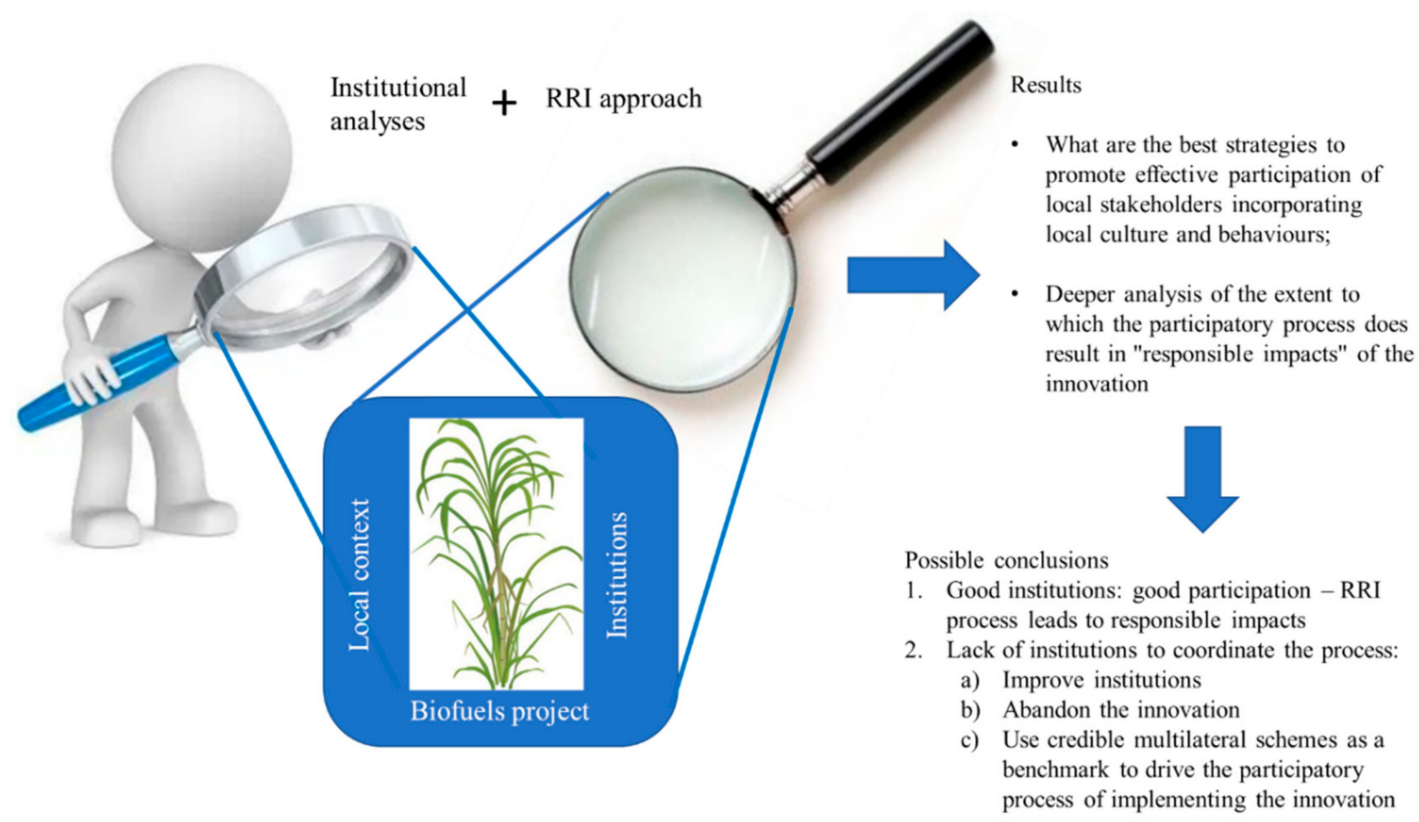

Figure 3. Complementing Responsible Research and Innovation Framework (RRI) analysis (created by the authors).

A preliminary institutional analysis is required to understand actors' ability in different contexts to implement effective participation. When local institutions can guarantee effective participation, the four pillars of RRI will probably achieve their aims. The participative process tends to generate positive impacts of the innovation, achieving the responsible innovation's ultimate goal.

However, when the institutional framework is not capable of coordinating the process (lack of trustable organization or properly enforcement power, for example), the institutional analysis helps to explore alternative strategies to improve local stakeholders' participation, taking into account their culture, value, beliefs and ways of interacting. In such cases, three possibilities are listed below, based on the literature referred to in the previous sections and the author's reflections:

(1) Improve institutions. As stressed by Taebi et al. [52] and Acemoglu and Robinson [60], this alternative is a lengthy process and one that requires strong political capabilities with solid social movements. Although it is the most laudable and sustainable alternative in the long run and hence it should be strived for continuously, it is not an option for some projects since institutional strengthening requires a longer timeframe than the innovation processes usually addressed by the RRI. It is possible that, in some cases of grassroots innovation (one which is raised from the ground or by the community), it may be an option.

(2) Abandon innovation. The second option, the most radical, should not be considered without in-depth institutional analysis. As discussed above, abandoning an innovation because the effective participation required in the RRI pillars are not strictly followed would impact communities and hinder the local development process. Would this effect be ethical and fair to local communities, just because the innovation process did not match the mindset of a framework designed externally? This option seems to be applied when the institutional analysis has demonstrated a lack of institutions that can minimally guarantee to use the RRI principles, therefore showing that no participatory process is possible. Even in this case however, the impacts of the innovation can be positive in amplifying the access to goods and services for a larger part of the population. Should such kind of innovation be called irresponsible because of the lack of a participative development process? Or its impact is what defines the responsible character of the innovation?

(3) Using alternative external schemes or standards as a trustable guide for a more participative implementation process. For example, the Sustainable Development Goal (SDG) or the IFC Standards, Principles of Responsible Investment, and other sectorial schemes aim to assure 
an inclusive and participatory process as principles of action. From this, it is possible to define strategies to guarantee the most participative process as possible (thus, responsible through the RRI lens and given that specific context) and, as a result, the accomplishment of positive outcomes in terms of inclusion, anticipation, reflexivity, and responsiveness.

It is important to emphasize that the three options above are alternatives to improve participation during the innovation development and implementation phases and raise the chances to achieve the positive impacts of the innovation. None of the options scanned guarantees that participation alone will produce outcomes aligned with society's needs. It depends on quality, diversity, critical skills, access to information, and other factors. It is precisely the problem of considering the framework to assess the responsible character of the Innovation. RRI is useful to inspire a participative process but what can be evaluated through the RRI approach is the process of participation and engagement, and not the innovation impact itself.

\section{Limitations}

Although mentioned in the literature review and discussion among our peers, we intentionally do not describe the contours of "strong" or good institutions because we do not want to repeat the mistake of crystallizing a vision of institutions that do not consider the local contexts that are naturally specific. The same reasoning is applied to the definition of the 'minimum requirements' for a trustable private sector organization to coordinate the development process when the institutions are not strong.

\section{Conclusions}

Worldwide biofuel expansion is essential if we are to transition to a biobased economy. In this sense, emerging technologies cannot disregard societies' social and environmental demands in which the innovations are implemented. Several frameworks emerged to assess how sustainable is the innovation in question, RRI among them.

To address the "responsible character of the innovation" as framed by RRI, it is important to understand what "responsible innovation" means. Is it the innovation that counted on stakeholders' effective participation during its development process or the innovation whose impacts are aligned with society's aims and needs? RRI framework seems to incorporate the premise that effective participation (as extracted from the good performance of the four pillars) will guarantee responsible impacts as defined by the participants and, therefore, the alignment of the innovation with the society needs.

However, there are three problems with this premise:

(1) It requires a quality of the participatory process dependent on culture, values, and behaviours that vary among the countries and regions. What makes it difficult to define upfront processual indicators that could assess effective participation quality in any context.

(2) Regarding the material elements that would generate indicators, metrics, and measurements to assess the responsible innovation impacts, those elements are dependent on the quality of the participation process. They cannot be upfront defined as common material metrics and indicators.

(3) Even when the process dimension of the innovation development in RRI does consider those contextual elements (culture and values) as fundamental requirements to perform effective participation, nothing can be predicted about how positive are the innovation's impacts. The improvements over the process of participation cannot automatically guarantee the positive impacts of the innovation.

Through the analysis of the literature about different case studies, we identified that conclusions about the responsible character of innovation that uses the RRI as an assessment tool usually reflect more the difficulties in applying the framework (the ideal participatory process in regions with a different culture, types of institutions and values) than the real "responsible" impact of the innovation 
in the study. RRI is a normative framework designed to influence the process of innovation and not to define the quality of the innovation's impacts.

We then conclude that using the RRI framework in regions of biofuels implementation projects reflects more the difficulties involved in applying guidelines that were, perhaps unconsciously, embedded with western values than the responsible character of the innovation impacts, which usually are defined upfront materially and measurably. Thus, RRI cannot be used as an assessment tool since it does not have the material metrics to measure how responsible or positive or negative the impacts of the innovation are implemented.

Irrespective of the critics, RRI remains a necessary normative framework to inspire and guide responsible innovation through the participatory process (the core element to the effectiveness of anticipation, reflexiveness, responsiveness, and inclusion) and achieve the innovation whose impacts are good for society. Its application should complement an initial analysis of institutions' quality to encapsulate local context and values. Understanding the institutional context before RRI application can help map the limitations and gaps and better define strategies to improve stakeholders' participation in the four pillars of the RRI framework and, consequently, raise the chances of promising outcomes regarding inclusive impacts of the innovation.

Future research should be carried out to understand whether innovation can be considered as responsible when substantive inclusion or effective participation is not entirely possible; whether it is possible to achieve inclusion as an outcome of a biofuel implementation project without proper participation (inclusion of process) in the innovation process, and how inclusive has the biofuel expansion been in different contexts.

Author Contributions: A.M.P., conceptualization, methodology, software, formal analysis, investigation, writing-original draft and review and editing, visualization; G.B., conceptualization, formal analysis, writing —original draft preparation, writing—review and editing; M.P.P. conceptualization, writing-review and editing; L.A., conceptualization, writing-review and editing, resources, supervision; P.O. conceptualization, writing-review and editing, supervision, validation, project administration, funding acquisition; J.M.F.J.D.S., conceptualization, validation, supervision, project administration, funding acquisition. All authors have read and agreed to the published version of the manuscript.

Funding: This study was financed in part by the Coordenação de Aperfeiçoamento de Pessoal de Nível Superior-Brasil (CAPES), finance Code 001 and by FAPESP—the São Paulo Research Foundation 2013/50950-5.

Conflicts of Interest: No potential conflict of interest was reported by the authors.

\section{References}

1. Blok, V.; Hoffmans, L.; Wubben, E.F.M. Stakeholder engagement for responsible innovation in the private sector: Critical issues and management practices. J. Chain Netw. Sci. 2015, 15, 147-164. [CrossRef]

2. Carbajo, R.; Cabeza, L.F. Renewable energy research and technologies through responsible research and innovation looking glass: Reflexions, theoretical approaches and contemporary discourses. Appl. Energy 2018, 211, 792-808. [CrossRef]

3. Eizagirre, A.; Rodríguez, H.; Ibarra, A. Politicizing Responsible Innovation: Responsibility as Inclusive Governance. Int. J. Innov. Stud. 2017. [CrossRef]

4. Hahn, J.; Ladikas, M. Responsible Research and Innovation: a Global Perspective. Enterp. Work Innov. Stud. 2014, 10, 9-27.

5. Blok, V.; Lemmens, P. The emerging concept of responsible innovation. Three reasons why it is questionable and calls for a radical transformation of the concept of innovation. In Responsible Innovation 2: Concepts, Approaches, and Applications; Koops, B.-J., Oosterlaken, I., Romijn, H., Swierstra, T., van den Hoven, J., Eds.; Springer International Publishing: Cham, Switzerland, 2015; pp. 19-35. ISBN 978-3-319-17307-8.

6. Timmermans, J. Mapping the RRI Landscape: an Overview of Organizations, Projects, Persons, Areas and Topics. In Responsible Innovation 3: A European Agenda? Asveld, L., van Dam-Mieras, R., Swierstra, T., Lavrijssen, S., Linse, K., van den, H.J., Eds.; Springer: Cham, Switzerland, 2017; pp. 21-48. ISBN 978-3-319-64834-7.

7. IRENA Trends in Renewable Energy. Available online: https://public.tableau.com/profile/irena.resource\#!/ vizhome/IRENARETimeSeries/Charts) (accessed on 16 July 2020). 
8. Sondergaard, N. Brazilian State-Agribusiness Relations within Global Processes of Regulatory Formation below the Corporate Food Regime; University of Brasilia: Brasilia, Brazil, 2018; Available online: https://repositorio. unb.br/handle/10482/34516 (accessed on 15 December 2020).

9. Bórawski, P.; Bełdycka-Bórawska, A.; Szymańska, E.J.; Jankowski, K.J.; Dubis, B.; Dunn, J.W. Development of renewable energy sources market and biofuels in The European Union. J. Clean. Prod. 2019, 228, 467-484. [CrossRef]

10. Frankfurt School-UNEP. Global Trends Renewable Energy 2020. 2020. Available online: https://www.fsunep-centre.org/global-trends-in-renewable-energy-investment-2020/ (accessed on 14 December 2020).

11. Proskurina, S.; Junginger, M.; Heinimö, J.; Tekinel, B.; Vakkilainen, E. Global biomass trade for energy-Part 2: Production and trade streams of wood pellets, liquid biofuels, charcoal, industrial roundwood and emerging energy biomass. Biofuels Bioprod. Biorefining 2019, 13, 371-387. [CrossRef]

12. Borras, S.M.; McMichael, P.; Scoones, I. The politics of biofuels, land and agrarian change: Editors' introduction. J. Peasant Stud. 2010, 37, 575-592. [CrossRef]

13. Miyake, S.; Renouf, M.; Peterson, A.; Mcalpine, C.; Smith, C. Land-use and environmental pressures resulting from current and future bioenergy crop expansion: A review. J. Rural Stud. 2012, 28, 650-658. [CrossRef]

14. Nassar, A.M.; Harfuch, L.; Bachion, L.C.; Moreira, M.R. Biofuels and land-use changes: Searching for the top model. Interface Focus 2011, 224-232. [CrossRef]

15. Schlesinger, S. Biofuels: Energy Won't Feed the Hungry; ActionAid Brazil: Rio de Janeiro, Brazil, 2014; Available online: https://actionaid.org/publications/2014/biofuels-energy-wont-feed-hungry (accessed on 15 December 2020).

16. Escobar, J.C.; Lora, E.S.; Venturini, O.J.; Yáñez, E.E.; Castillo, E.F.; Almazan, O. Biofuels: Environment, technology and food security. Renew. Sustain. Energy Rev. 2009, 13, 1275-1287. [CrossRef]

17. Richard, T. Ask the Experts: The food versus fuel debate. Biofues 2012, 3, 635-648.

18. Rosillo-Calle, F. Food versus Fuel: Toward a New Paradigm-The Need for a Holistic Approach. ISRN Renew. Energy 2012, 2012, 1-15. [CrossRef]

19. Mol, A.P.J. Boundless biofuels? Between environmental sustainability and vulnerability. Sociol. Ruralis 2007, 47, 297-315. [CrossRef]

20. Gallardo, A.L.C.F.; Bond, A. Capturing the implications of land use change in Brazil through environmental assessment: Time for a strategic approach? Environ. Impact Assess. Rev. 2011, 31, 261-270. [CrossRef]

21. Ribeiro, B.E. Beyond commonplace biofuels: Social aspects of ethanol. Energy Policy 2013, 57, 355-362. [CrossRef]

22. Filoso, S.; Do Carmo, J.B.; Mardegan, S.F.; Lins, S.R.M.; Gomes, T.F.; Martinelli, L.A. Reassessing the environmental impacts of sugarcane ethanol production in Brazil to help meet sustainability goals. Renew. Sustain. Energy Rev. 2015, 52, 1847-1856. [CrossRef]

23. Ciervo, M.; Schmitz, S. Sustainable biofuel: A question of scale and aims. Morav. Geogr. Rep. 2017, 25, 220-233. [CrossRef]

24. Martinelli, L.A.; Filoso, S. Balance between food production, biodiversity and ecosystem services in Brazil: A challenge and an opportunity. Biota Neotrop. 2009, 9, 21-25. [CrossRef]

25. Wilkinson, J.; Herrera, S. Biofuels in brazil: Debates and impacts. J. Peasant Stud. 2010, 37, 749-768. [CrossRef]

26. Pilgrim, S.; Harvey, M. Battles over biofuels in Europe: NGOs and the politics of markets. Sociol. Res. Online 2010, 15. [CrossRef]

27. Tilman, D.; Socolow, R.; Foley, J.A.; Hill, J.; Larson, E.; Lynd, L.; Pacala, S.; Reilly, J.; Searchinger, T.; Somerville, C.; et al. Beneficial Biofuels_The Food, Energy, and Environment Trilemma. Science 2009, 325, 270-271. [CrossRef] [PubMed]

28. Harvey, M.; Pilgrim, S. The new competition for land: Food, energy, and climate change. Food Policy 2011, 36, 1-12. [CrossRef]

29. Assato, M.M.; de Moares, M.A.F.; de Oliveira, F.C.R. Impactos sócio-econômicos da expansão do setor bioenergético no estado do Mato Grosso do Sul: Os casos dos municípios de Nova Alvorada do Sul e Rio Brilhante. In Proceedings of the 49o Congresso da Sober, Belo Horizonte, Brazil, 24-27 July 2011; Available online: https://bv.fapesp.br/pt/auxilios/78723/49o-congresso-da-sociedade-brasileira-de-economiaadministracao-e-sociologia-rural-sober/ (accessed on 15 December 2020).

30. Bacchi, M.R.P.; Caldarelli, C.E. Impactos socioeconômicos da expansão do setor sucroenergético no Estado de São Paulo, entre 2005 e 2009. Nov. Econ. 2015, 25, 218. [CrossRef] 
31. Diaz-Chavez, R.A. Assessing biofuels: Aiming for sustainable development or complying with the market? Energy Policy 2011, 39, 5763-5769. [CrossRef]

32. van Eijck, J.; Faaij, A.P.C. Socio-Economic Impacts of Bioenergy Production; Rutz, D., Janssen, R., Eds.; Springer International Publishing: Cham, Switzerland, 2014; ISBN 978-3-319-03828-5.

33. Moraes, M.A.F.D.; Oliveira, F.C.R.; Diaz-Chavez, R.A. Socio-economic impacts of Brazilian sugarcane industry. Environ. Dev. 2015, 16, 31-43. [CrossRef]

34. Rutz, D.; Janssen, R. Socio-economic impacts of biofuels on land use change. In Socio-Economic Impacts of Bioenergy Production; Biomass, D.R., Janssen, R., Eds.; Springer: Munich, Germany, 2014; Volume 9783319038, pp. 81-93. ISBN 978-3-319-03829-2.

35. GNESD. Bioenergy: The Potential for Rural Development and Poverty Alleviation. Global Network on Energy for Sustainable Development (GNESD). Summary for Policy-Makers. 2011. Available online: https://orbit. dtu.dk/en/publications/bioenergy-the-potential-for-rural-development-and-poverty-allevia (accessed on 15 December 2020).

36. Creutzig, F.; Corbera, E.; Bolwig, S.; Hunsberger, C. Integrating place-specific livelihood and equity outcomes into global assessments of bioenergy deployment. Environ. Res. Lett. 2013, 8. [CrossRef]

37. Souza, L.G.A.; Moraes, M.A.F.D.; Dal Poz, M.E.S.; Silveira, J.M.F.J. Collaborative Networks as a measure of the Innovation Systems in second-generation ethanol. Scientometrics 2015, 103, 355-372. [CrossRef]

38. Bueno, C.D.S.; Silveira, J.M.F.J.; Buainain, A.M. Innovation, networks and the paradigm of biofuels. Int. J. Entrep. Small Bus. 2018, 35, 452-484. [CrossRef]

39. Pashaei Kamali, F.; Borges, J.A.R.; Osseweijer, P.; Posada, J.A. Towards social sustainability: Screening potential social and governance issues for biojet fuel supply chains in Brazil. Renew. Sustain. Energy Rev. 2018, 92, 50-61. [CrossRef]

40. Mousavi, S.; Bossink, B. Corporate-NGO partnership for environmentally sustainable innovation: Lessons from a cross-sector collaboration in aviation biofuels. Environ. Innov. Soc. Transit. 2020, 34, 80-95. [CrossRef]

41. Fortin, E. Transnational multi-stakeholder sustainability standards and biofuels: Understanding standards processes. J. Peasant Stud. 2013, 40, 563-587. [CrossRef]

42. Owen, R.; Macnaghten, P.; Stilgoe, J. Responsible research and innovation: From science in society to science for society, with society. Sci. Public Policy 2012, 39, 751-760. [CrossRef]

43. Stilgoe, J.; Owen, R.; Macnaghten, P. Developing a framework for responsible innovation. Res. Policy 2013, 42, 1568-1580. [CrossRef]

44. De Hoop, E.; Pols, A.; Romijn, H. Limits to responsible innovation. J. Responsible Innov. 2016, 3, 110-134. [CrossRef]

45. Macnaghten, P.; Owen, R.; Stilgoe, J.; Wynne, B.; Azevedo, A.; de Campos, A.; Chilvers, J.; Dagnino, R.; di Giulio, G.; Frow, E.; et al. Responsible innovation across borders: Tensions, paradoxes and possibilities. J. Responsible Innov. 2014, 1, 191-199. [CrossRef]

46. Asveld, L.; Ganzevles, J.; Osseweijer, P. Trustworthiness and Responsible Research and Innovation: The Case of the Bio-Economy. J. Agric. Environ. Ethics 2015, 28, 571-588. [CrossRef]

47. Asveld, L.; van Dam-Mieras, R. Introduction: Responsible Research and Innovation for Sustainability. In Responsible Innovation 3; Asveld, L., van Dam-Mieras, R., Swierstra, T., Lavrijssen, S., Linse, K., van den Hoven, J., Eds.; Springer International Publishing: Cham, Switzerland, 2017; pp. 1-6. ISBN 978-3-319-64834-7.

48. Wong, P.H. Responsible innovation for decent nonliberal peoples: a dilemma? J. Responsible Innov. 2016, 3, 154-168. [CrossRef]

49. Bronson, K. Diversity by design: Substantive inclusion for transformative agricultural value chains. In Proceedings of the IBIS Seminar-Building Inclusive Agricultural Value Chains Online Seminar Series; Biotechnology \& Society Section at TU Delft, Business Management \& Organisation Division: Delft, The Netherlands, October 2020.

50. Noorman, M.; Swierstra, T.; Zandbergen, D. Questioning the Normative Core of RI: The Challenges Posed to Stakeholder Engagement in a Corporate Setting. In Responsible Innovation 3; Springer International Publishing: Cham, Switzerland, 2017; pp. 231-249. ISBN 978-3-319-64834-7.

51. Stober, D.; Suškevičs, M.; Eiter, S.; Müller, S.; Martinát, S.; Buchecker, M. What is the quality of participatory renewable energy planning in Europe? A comparative analysis of innovative practices in 25 projects. Energy Res. Soc. Sci. 2021, 71. [CrossRef] 
52. Taebi, B.; Correljé, A.; Cuppen, E.; Dignum, M.; Pesch, U. Responsible innovation as an endorsement of public values: The need for interdisciplinary research. J. Responsible Innov. 2014, 1, 118-124. [CrossRef]

53. Callon, M.; Lascoumes, P.; Barthe, Y. Acting in an Uncertain World-An Essay on Technical Democracy; The MIT Press: Cambridge, MA, USA, 2009; ISBN 978-0-262-03382-4.

54. Pansera, M.; Owen, R. Framing inclusive innovation within the discourse of development: Insights from case studies in India. Res. Policy 2018, 47, 23-34. [CrossRef]

55. Setiawan, A.D.; Singh, R. Responsible innovation in practice: The adoption of solar PV in telecom towers in Indonesia. In Responsible Innovation 2: Concepts, Approaches, and Applications; Springer International Publishing: Cham, Switzerland, 2015; pp. 225-244. ISBN 9783319173085.

56. Ostrom, E. Designing Complexity to Govern Complexity; World Bank: Washington, DC, USA, 1995; ISBN 0821334158.

57. Wells, P.; Zapata, C. Eco-industrialism: The Potential for Inclusive Growth with Bio-Plastic Production in Brazil Using Sugarcane Ethanol. In Proceedings of the 3rd International Workshop: Advances in Cleaner Production, São Paulo, Brazil, 18-20 May 2011.

58. Feinberg, R.; Stein, E.; Tommasi, M.; Echebarría, K.; Lora, E.; Payne, M. The Politics of Policies: Economic and Social Progress in Latin America, 2006 Report. Foreign Aff. 2006, 85, 169. [CrossRef]

59. Barney, J.B.; Nelson, R.R.; Winter, S.G. An Evolutionary Theory of Economic Change; Havard University Press: Cambridge, MA, USA, 1987; Volume 32, ISBN 0674272285.

60. Acemoglu, D.; Robinson, J. Why Nations Fail: The Origins of Power, Prosperity and Poverty; Business, C., Ed.; Elsevier Ltd.: Washington, DC, USA, 2012; ISBN 978-0307719219.

61. Ostrom, E. Understanding Institutional Diversity, 2005th ed.; Princeton University Press: Princeton, NJ, USA, 2005; Volume 132, ISBN 9780691122076.

62. Wickson, F.; Carew, A.L. Quality criteria and indicators for responsible research and innovation: Learning from transdisciplinarity. J. Responsible Innov. 2014, 1, 254-273. [CrossRef]

63. Levitsky, S.; Murillo, M.V. Building Institutions on Weak Foundations. J. Democr. 2013, 24, 93-107. [CrossRef]

64. Randles, S.; Youtie, J.; Guston, D.H.; Shapira, P.; Wickson, F.; Rip, A. A Transatlantic Conversation on Responsible Innovation and Responsible Governance. In Proceedings of the Annual Meeting of the Society for the Study of Nanocience and Emerging Technologies (S.NET), Enschede, The Netherlands, 22-25 October 2012.

65. Vasen, F. Responsible Innovation in Developing Countries: An Enlarged Agenda. In Responsible Innovation 3; Springer International Publishing: Cham, Switzerland, 2017; pp. 93-109. ISBN 9783319648347.

66. Marques Postal, A.; Pashaei Kamali, F.; Asveld, L.; Osseweijer, P.; da Silveira, J.M.F.J. The impact of sugarcane expansion in Brazil: Local stakeholders' perceptions. J. Rural Stud. 2020, 73, 147-162. [CrossRef]

67. Balkema, A.; Pols, A. Biofuels: Sustainable Innovation or Gold Rusch? Identifying Responsibilities form Biofuels Innovations. J. Responsible Innov. 2014, 56, 283-303. [CrossRef]

68. Chaturvedi, S.; Ravi Srinivas, K.; Kumar, A. Agriculture technology choices and the responsible research and innovation (RRI) framework: Emerging experiences from China and India. Asian Biotechnol. Dev. Rev. 2016, $18,93-111$.

69. Hartley, S.; McLeod, C.; Clifford, M.; Jewitt, S.; Ray, C. A retrospective analysis of responsible innovation for low-technology innovation in the Global South. J. Responsible Innov. 2019, 6, 143-162. [CrossRef]

70. Voeten, J.J.; Naudé, W.A. Regulating the negative externalities of enterprise cluster innovations: Lessons from Vietnam. Innov. Dev. 2014, 4, 203-219. [CrossRef]

71. De Campos, A.S.; Hartley, S.; de Koning, C.; Lezaun, J.; Velho, L. Responsible Innovation and political accountability: Genetically modified mosquitoes in Brazil. J. Responsible Innov. 2017, 4, 5-23. [CrossRef]

Publisher's Note: MDPI stays neutral with regard to jurisdictional claims in published maps and institutional affiliations. 